\title{
The Acquisition of Classical Origin Words by Chinese, French, and Finnish Learners
}

\author{
Simon Smith \\ Coventry University, England \\ Nicole Keng \\ Xi'an Jiaotong Liverpool University, Suzhou, China
}

\begin{abstract}
This comparative study evaluates the vocabulary knowledge of comparable groups of English learners from three L1 backgrounds: French, Finnish, and Mandarin Chinese. An investigation of differences in vocabulary knowledge revealed that vocabulary of Greek or Latin origin is much more likely to be known by French speaking students than words of non Graeco-Latin origin. Finnish students did much better on words of non Graeco-Latin origin, although they still outperformed the French speakers on Graeco-Latin words. The performance of the native Chinese speakers was the worst of the three groups, and there was no significant difference with this group between the two sets of words. The findings have clear implications for the teaching of academic English vocabulary in EAP settings where students share an L1. In mixed L1 settings, instructors may need to take account of variation in vocabulary knowledge among different L1 student groups.
\end{abstract}

As is widely known, a large proportion of English vocabulary is of Graeco-Latin (GL) origin. Most native English speakers would agree that frequent use of GL words could be an indication of a greater vocabulary and indeed of a higher level of education. Corson $(1982,1985)$, posited the existence of a lexical bar in English, whereby members of certain social classes, who do not acquire the L1 vocabulary necessary to express more abstract technical and academic thought, are denied full access to the curriculum as they go through the school system. In English, a high proportion of scientific and technical terms take the form of GL words. GL words are more difficult to acquire inasmuch as specialist vocabulary tends to represent more difficult concepts.

Whilst social class, prosperity, and a range of other environmental factors may influence the degree to which Asian learners acquire English, it is of course extremely unlikely that such factors have any impact on the type of vocabulary learned. However, the lack of GL cognates in a given language will probably place its native speakers at a disadvantage when learning English vocabulary. It can plausibly be argued that a lexical bar similar to Corson's exists for certain EFL learners; the height of this bar would be in inverse proportion to the density of GL

Language Education in Asia, 2013, 4(2), 122-134. http://dx.doi.org/10.5746/LEiA/13/V4/I2/A03/Smith_Keng 
cognates in the language. In this study, it is predicted that native speakers of Asian languages which have very few GL cognates will have a lesser knowledge of English GL words than speakers of languages that do attest such cognates. The Asian learners investigated in the study are Chinese; in future work, it will be of interest to study Asian learners whose L1 does incorporate GL cognates, such as Khmer and Filipino (which have GL cognates borrowed via French and Spanish respectively).

The study looked at 3 groups: learners with L1 Chinese (Mandarin), French, and Finnish. In French, almost all the lexical stock consists of words of Greek or Latin origin. Finnish also has a substantial number of such words, for example, tragedia, komedia, optimisti, pessimisti (although not as many as occur in Indo-European languages). Chinese, which belongs to the Sino-Tibetan language family, has no more than a handful of GL loanwords, such as youmò (humor) and luóji (logic), but these are borrowed from English in any case. It is therefore plausible that Finnish learners will have a better knowledge of words of Greek or Latinate origin than their Chinese counterparts. One would expect French learners to have a better knowledge of these English words than Finns or Chinese.

It makes intuitive sense that the use of L1 knowledge will be of assistance in acquiring L2 vocabulary cognates. Cobb (2000, p. 316), for example, found that French-speaking students' English vocabulary depended so heavily on their knowledge of L1 cognates that they could "answer questions about English words that they have not necessarily learned through exposure to English." Equally intuitively, the cognate knowledge may not be readily available to Chinese students. The present study seeks to confirm these intuitions by measuring and comparing the GL and non-GL vocabulary knowledge of three representative groups.

It was hypothesized that, of the three L1 groups studied, Finnish students would exhibit the best knowledge of academic English vocabulary on a test including words of mixed origins (GL and non-GL). On a test which included only GL words, it was predicted that the French speakers would perform best because French has more GL origin words. It was further hypothesized that the Chinese learners would perform the worst on both tests.

These hypotheses can be expressed as follows:

H1. All words: Finnish $>$ French $>$ Chinese

H2. GL words: French $>$ Finnish $>$ Chinese

In H1, "AlI" refers to the set of GL and non-GL words, that is, the set of all English words.

Several studies have investigated the academic word knowledge of learners from particular L1 backgrounds. Henriksen (2012, for Danish) and Nurweni and Read (1999, for Indonesian) both found that breadth of knowledge of academic vocabulary (vocabulary used in the writing of students or academics) was surprisingly low. However, no special attention has been paid in the literature to learners' knowledge of GL words across different L1 groups. The present study compares the students' knowledge of GL and non-GL words from an academic word list, the British Academic Written English corpus (BAWE), as well as the relationship between this knowledge and the L1 background. The BAWE corpus is described by Nesi and Gardner (2012): it contains 3,000 British university student writing assignments at first or upper second standard (graded at $60 \%$ or above), totalling 6.5 million words, in four broad disciplinary areas (Arts and Humanities, Social Sciences, Life Sciences and Physical Sciences) and across four levels of study (undergraduate and taught masters level). Thirty main disciplines are represented. The word list used is described in the Methodology section below. 


\section{Vocabulary Tests}

The first task was to determine the appropriate tool or test for quantifying vocabulary knowledge. Whilst of course the desired test would be as accurate as possible, the research interest was in the mean performance of a group (of speakers of a particular L1), not that of individuals. The need for a tool which could be administered quickly to a large group of students outweighed the need for recording the performance of individuals. Any tool which relied on translation from or to the participant's L1, such as the Computer Adaptive Test of Size and Strength (CATSS), described by Laufer and Goldstein (2004) was ruled out, because the purpose of the task was to compare different $L 1$ group performances. If such a tool had been used, different versions for French, Finnish and Chinese would have been needed, and it would have been impossible to guarantee translational equivalence between English and the three L1s.

Tests which attempt to quantify vocabulary depth are in fact making an estimate of the number of words a testee is likely to know, rather than actually counting them. Essentially, a number of words at more than one frequency band are sampled, in order to ascertain a learner's vocabulary size or level. The level or size can then be used to predict what the learner can do with the language: 2,000 words for basic communication, 5,000 words to read authentic texts, and 10,000 words to cope with a university course in English (Schmitt, Schmitt, \& Clapham, 2001).

The Vocabulary Size Test (VST; Nation \& Gu, 2007) and Vocabulary Levels Test (VLT; Nation, 1990) measure vocabulary breadth by the use of distractors. A typical VLT item provides the testees with six words at a given frequency level, along with definitions of only three of the words. They must then select the correct definition of the three words, ignoring the three distractor words. Figure 1 shows a typical VLT item.

\begin{tabular}{|c|c|c|c|}
\hline 1. original & & 1. apply & \\
\hline 2. private & complete & 2. elect & voting \\
\hline 3. royal & firct & 3. jump & become \\
\hline 4. slow & IIISt & 4. manufacture & like water \\
\hline 5. sorry & not public & 5. melt & make \\
\hline 6. total & & 6. threaten & \\
\hline
\end{tabular}

Figure 1. A VLT item from the 2,000 word level.

In the VST, the testees are given one word, an example of the use of the word in a sentence, and a choice of four definitions for the word of which only one is correct.

Although the validity of the VST and VLT has to some extent been established by studies involving post-test interviews (Schmitt et al., 2001; Vilkaitè, Gyllstad, \& Schmitt, 2013), these tests are quite time-consuming to administer, permitting only a relatively small sampling rate. As with all distractor-based tests, problems are bound to arise. On the VST found at http://my.vocabularysize.com, for example, the correct definition for the item many is "a large number," as can be seen from Figure 2. However, it is impossible to imagine that a learner of any nationality would know the distractor "enough" and not know "many"; thus, it is not the knowledge of the target item that is actually being tested here. On the same test, the correct definition for the item hutch is given in four words (cage for small animals), while all three distractor definitions contain 10 or more words, so that the test-taker is led visually towards selection of the key. 


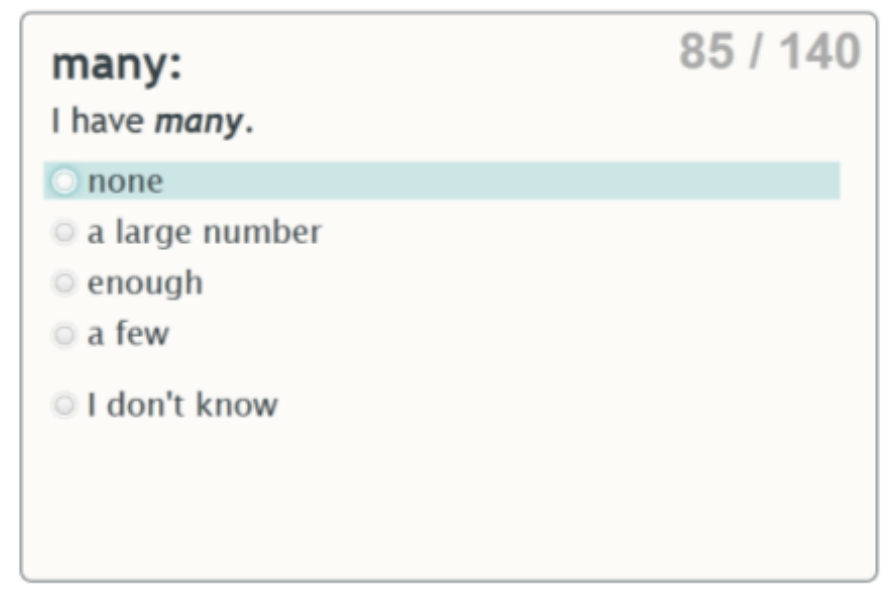

Figure 2. A VST item from http://my.vocabularysize.com.

\section{Yes / No Tests}

The yes / no test format was first described as a means of measuring L2 vocabulary knowledge by Meara and Buxton (1987). Essentially, it consists of asking the testees whether or not they "know" the words in the sample. The advantage of the yes / no test is that it is easy to administer to a large number of testees, and a large number of items can be tested. The test is easy to develop (there are no test items to write or contexts to come up with) and it can be marked quickly and automatically.

There are disadvantages, too. It has been claimed that testees of certain L1 backgrounds may have different response patterns; for example, Cobb (2000) found that native Arabic speakers were more likely to report that they knew words that merely resembled words they had actually encountered. Since Arabic speakers were not being studied, this was not of great concern in this research. More disconcerting is a tendency reported by Meara and Jones (1990) for French speakers to report that they are familiar with English words which are identical in form to equivalent French words, even though they have not met the word in English. In the present study, the GL words are often French cognates; infiltrate, for example, is infiltrer in French, while transformations is spelled the same in both languages. As noted below this may have had an impact on standard deviations among French participants in this study.

Clearly, there is a risk with the yes / no test that certain testees might respond dishonestly, claiming to know words that they have never seen before. For this reason, Meara and his colleagues (Huibregtse, Admiraal, \& Meara, 2002; Meara \& Buxton, 1987; Meara \& Jones, 1990) adopted the use of pseudo-words, which are mixed in with the real words in the sample. Since the pseudo-words are not part of the lexicon, the testees cannot possibly know them; if they do claim to know any, a penalty can be applied which causes an appropriate impact on the number of actual words claimed to be known.

The simplest way to apply a penalty is to subtract the number of false alarms (the number of pseudo-words that the testee claims to know) from the number of real words claimed to be known (Pellicer-Sánchez \& Schmitt, 2012). This can be represented as (1), where $P(h)$ represents the probability that the testee knows the word.

(1) $P(h)=h-f$ 
However, Huibregtse, Admiraal, and Meara (2002) noted that this way of calculating the penalty does not properly reflect individual response styles. In particular, a testee responding conservatively (only responding when absolutely certain of knowing the item) will get a lower overall score than someone inclined to take risks and claim knowledge of words which they are not familiar with. This may apply even though the actual vocabulary knowledge of the two testees is the same. One correction algorithm that does take better account of individual response styles is Signal Detection Theory Index $\left(\mathrm{I}_{\mathrm{SDT}}\right)$, also presented by Huibregtse et al. This is calculated as per (2).

(2) $P(h)=1-\frac{2 h(1-f)-(h-f)(1+h-f)}{4 h(1-f)-(h-f)(1+h-f)}$

In the present paper, penalties were calculated using both the $h-f$ and $I_{\mathrm{SDT}}$ algorithms, and some comparison of the two approaches is provided in the Results and Discussion section.

\section{Methodology}

Vocabulary knowledge of the two groups was tested by the yes / no test, in which learners are shown sets of words at different frequency levels. The tests include pseudo-words of the same approximate length and apparent morphological complexity as the real words being shown. The learners were asked to indicate which words they knew, and a penalty was applied for claiming to know a pseudo-word.

Data were collected from students following Engineering or Business Studies courses in one of two universities: one in the UK, the other in Finland. All were enrolled in Academic English programmes designed to support their main course of study, and the English teachers administered the tests. The students were in seven class groups: four in the UK and three in Finland. Participants were selected randomly from Academic English programmes at the two universities. There were $19 \mathrm{~L} 1 \mathrm{~s}$ in the group of 125 students which took part in the tests, but only responses from French $(n=21)$, Mandarin Chinese $(n=33)$, and Finnish $(n=41)$ native speakers were analysed. These three L1s were selected because they constituted the largest L1 groups, and because they contain different proportions of GL vocabulary: high, in the case of French, medium (Finnish), and low (Chinese). The students had IELTS scores of between 5.5 and 7, which represents a broad range of proficiencies: this is acknowledged as a limitation of the study, but as discussed in the Limitations section, does not invalidate the work, because it is the difference in knowledge of GL and non-GL vocabulary that is investigated, rather than overall vocabulary knowledge.

Words were selected from the BAWE corpus, which contains academic writing graded $60 \%$ or above by students at UK universities. Because the goal of this study was to compare knowledge of academic English (rather than general English) among the L1 groups, a first thought was to use the Academic Word List (Coxhead, 2000) as the word source. However, it turned out that almost all AWL words are of Graeco-Latin origin, whilst what was needed was a source which could provide both GL and Germanic words used in academic writing, at a range of frequencies. Reference was made to the list of $21,000+$ word types that appear 10 or more times in the corpus. The most frequent, of course, is the, while barbarous, clothe and orator are among those at the lower end of the list; thus, it is not so much a list of academic words as a list of all words that are likely to occur in academic writing.

A pre-pilot study revealed that items towards the bottom of the BAWE frequency list were too difficult for the students, yielding few correct answers. Since the high frequency words would 
clearly have been too easy, mid-range items, occurring 34 times in the corpus, were selected. At this level, there were considerably more GL than Germanic words. The procedure used for word selection was to scroll down the list (which is in an arbitrary order within the frequency blocks) until a Germanic word was encountered, select that, then select the GL word immediately following. Non-standard words (such as $\mathrm{rev} / \mathrm{min}$ ) and proper names were not selected. Figure 3 shows excerpts from the beginning, middle, and end of the wordlist spreadsheet.

\begin{tabular}{|c|c|c|c|}
\hline 4 & & & B \\
\hline $1 \mathrm{~V}$ & WORD & $\nabla$ & no. occurrences - \\
\hline $2 \mathrm{th}$ & the & & 492272 \\
\hline $3 \mathrm{~b}$ & be & & 289343 \\
\hline 40 & of & & 271079 \\
\hline 5 a & and & & 208696 \\
\hline 6 tc & to & & 191632 \\
\hline 7 ir & in & & 153337 \\
\hline $8 a$ & a & & 136398 \\
\hline $9 \mathrm{th}$ & that & & 79337 \\
\hline 10013 & 3 craftsman & & 34 \\
\hline 10014 & 4 acquaintance & & 34 \\
\hline 10015 & 5 duchess & & 34 \\
\hline 10016 & 6 lust & & 34 \\
\hline 10017 & 7 infiltrate & & 34 \\
\hline 10018 & 8 homogeneity & & 34 \\
\hline 10019 & 9 noisy & & 34 \\
\hline 10020 & 0 outright & & 34 \\
\hline 10021 & 1 seventeenth-century & & 34 \\
\hline 21588 & 38 bewildered & & 10 \\
\hline 21589 & 39 carve & & 10 \\
\hline 21590 & o barbarous & & 10 \\
\hline 21591 & 1 well-ordered & & 10 \\
\hline 21592 & 2 luxemburg & & 10 \\
\hline 21593 & 3 filmer & & 10 \\
\hline 21594 & 4 rendering & & 10 \\
\hline 21595 & 5 commonsense & & 10 \\
\hline 21596 & 6 coulter & & 10 \\
\hline 21597 & 7 clothe & & 10 \\
\hline 21598 & 8 orator & & 10 \\
\hline 21599 & 9 uncomplicated & & 10 \\
\hline
\end{tabular}

Figure 3. Excerpts from the beginning, middle and end of the BAWE word list frequency spreadsheet. The middle section was actually used.

In cases where the authors were not certain of the etymology of a word, a check was made at an etymology website (www.etymonline.com). Words were chosen without taking account of part of speech or other lexical features.

Twenty-five GL words and 25 Germanic words from the middle of the BAWE list were selected. A random word generator (http://nexi.com/fun/) was used to generate sets of pseudo-words by seeding it with the selected words. In this way, lists of "Graeco-Latin" pseudo-words and "Germanic" pseudo-words were created. The complete list of words used (50 real words and 25 pseudo-words) is shown in Table 1. Readers may wish to evaluate for themselves the plausibility of the pseudo-words. 
Table 1

Items Used in Yes / No Test

\begin{tabular}{|c|c|}
\hline Graeco-Latin & Germanic \\
\hline flour & dare \\
\hline noise & craftsman \\
\hline infiltrate & lust \\
\hline transformations & outright \\
\hline deconstruct & breadwinner \\
\hline antagonistic & greatness \\
\hline cyclotron & limestone \\
\hline agitation & handy \\
\hline anoxia & mast \\
\hline speciality & sliding \\
\hline habitual & bowl \\
\hline imperfection & skewness \\
\hline triplet & sender \\
\hline kilometre & healer \\
\hline filtration & spear \\
\hline intercultural & fur \\
\hline pleased & weep \\
\hline catastrophe & bother \\
\hline abbey & brick \\
\hline ceremonial & rot \\
\hline memoir & killer \\
\hline suitably & folk \\
\hline ensue & akin \\
\hline primatology & womb \\
\hline incisor & yogurt \\
\hline
\end{tabular}

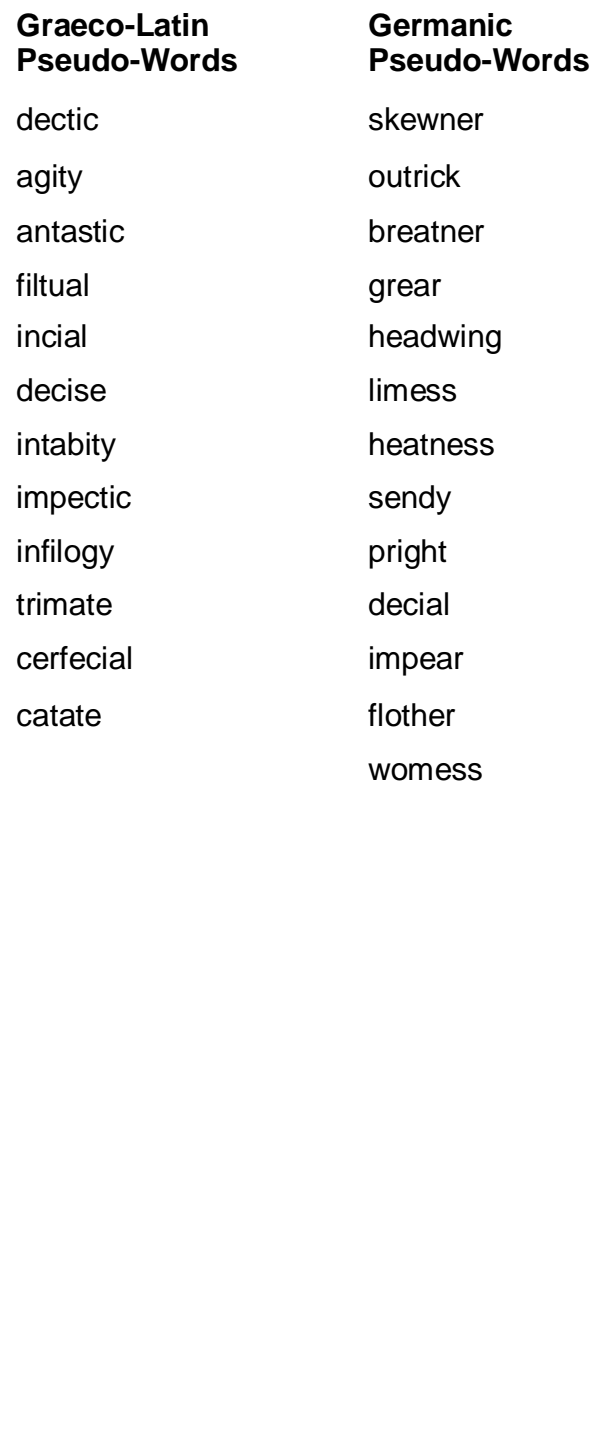

\section{Procedure}

The yes / no tests were administered anonymously at the end of ordinary English teaching sessions. Students were asked to sign an agreement form if they wished to take part, and all those present did. No incentive or payment was offered for participation. On the answer sheets (separate from the agreement form), students were asked to note their native language.

The 75 words and pseudo-words were shuffled using a random number generator (www.random.org). Participants were told that not all the words to be displayed were real words, and that they should avoid speaking to each other or registering surprise. Each word was displayed in a large font on a PowerPoint slide for 5-6 seconds. Participants then had to tick the appropriate cell in a column headed "Yes" if they knew the word, and one headed "No" if they did not know it.

After the results had been tabulated, composite scores for each student were computed using both the $h$ - $f$ and $\mathrm{I}_{\mathrm{SDT}}$ hit rate calculation methods, as previously explained, for GL words and Germanic words. The mean score among all participants of a given L1 was also recorded. 


\section{Results and Discussion}

It was found that that GL words are much more likely to be known by French speaking students than non-GL words. Finnish students did much better on words of non Graeco-Latin origin, although they still outperformed the French speakers on all vocabulary. The performance of the native Chinese speakers was the worst of the three groups, and there was no significant difference with this group between the two sets of words.

The first hypothesis, regarding knowledge of "all" words (both GL and Germanic), was thus confirmed. Finnish learners scored highest on the yes / no test, followed by French learners, with Chinese in third place. The finding applied to both scoring algorithms, as shown in Table 2 .

\section{Table 2}

Hit Rates for All Words

\begin{tabular}{lcccc}
\hline & Mean $\boldsymbol{h}-\boldsymbol{f}$ rate & $\boldsymbol{S D}$ & Mean ISDT rate & SD \\
\hline Finnish & 0.48195 & 0.0717 & 0.54440 & 0.0720 \\
French & 0.36761 & 0.0602 & 0.46880 & 0.0543 \\
Chinese & 0.27313 & 0.0747 & 0.39687 & 0.0690 \\
\hline
\end{tabular}

The second hypothesis, that the French learners would take first place when it came to GL words was, however, not supported. Table 3 shows that Finnish learners still scored highest when scored only on GL words, indicating that they know more GL words than the other two groups of learners.

\section{Table 3}

Hit Rates for GL Words

\begin{tabular}{lcccc}
\hline & Mean $\boldsymbol{h}-\boldsymbol{f}$ rate & $\boldsymbol{S D}$ & Mean ISDT rate & SD \\
\hline Finnish & 0.44993 & 0.0796 & 0.52071 & 0.0854 \\
French & 0.42481 & 0.0548 & 0.50793 & 0.0469 \\
Chinese & 0.25199 & 0.0739 & 0.39094 & 0.0813 \\
\hline
\end{tabular}

However, the results also indicate that French learners have a better knowledge of GL words than non-GL words, while the reverse is true for Finns (even though the latter group know more overall in both categories). This finding, along with the two hypothesis outcomes noted above, is presented in Figure 4 in percentage form. 

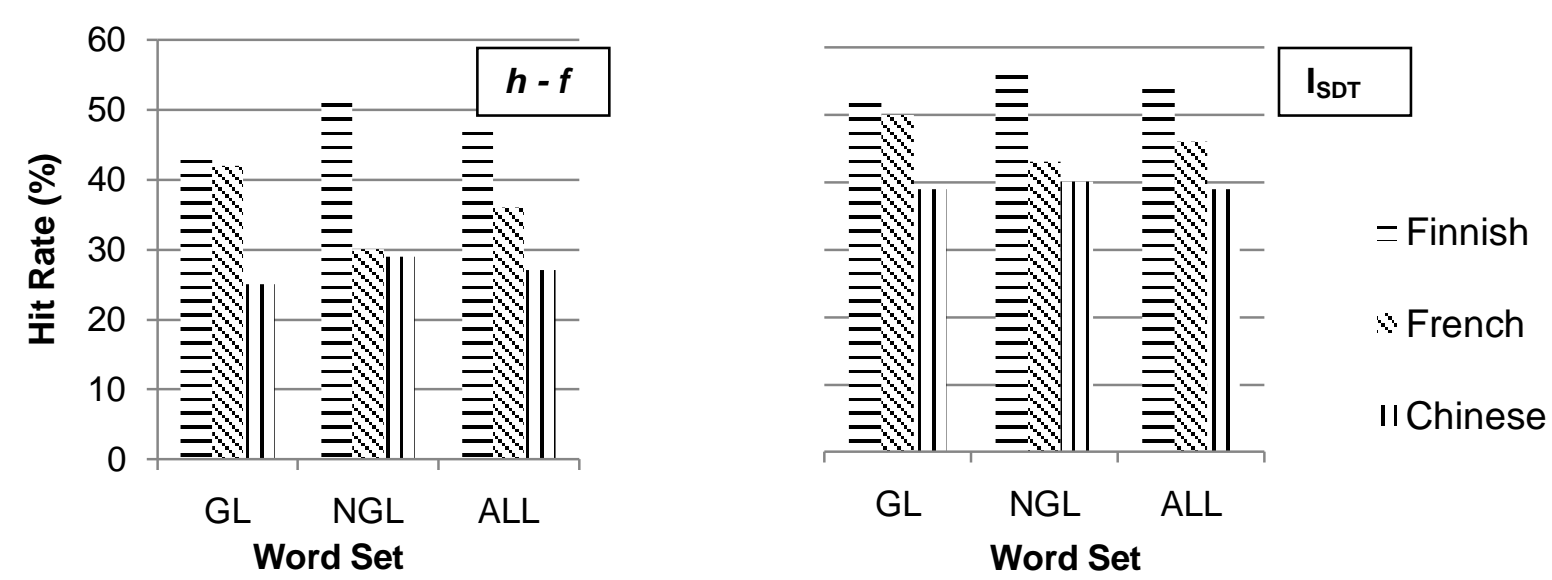

Figure 4. Hit rates for all word types, all L1s.

Figure 4 shows the relative performance of the three language groups on GL and non-GL words. It can be seen that the same findings broadly apply, whichever algorithm $\left(h-f_{\mathrm{O}} \mathrm{I}_{\mathrm{SDT}}\right)$ is used for calculating scores.

Table 4

Paired T-Test, GL Words vs. non-GL Words

\begin{tabular}{|c|c|c|c|c|}
\hline & & $\begin{array}{c}\text { Non-GL vs. GL } \\
\text { difference }\end{array}$ & $S D$ & Sig. \\
\hline \multirow[t]{2}{*}{ Finnish } & $h$ - frate & .06473 & .07024 & .000 \\
\hline & $\mathrm{I}_{\mathrm{SDT}}$ rate & .05041 & .07960 & .000 \\
\hline \multirow[t]{2}{*}{ French } & $h$ - frate & -.12876 & .07955 & .000 \\
\hline & $\mathrm{I}_{\mathrm{SDT}}$ rate & -.07624 & .05518 & .000 \\
\hline \multirow[t]{2}{*}{ Chinese } & $h$ - frate & .04703 & .09024 & .005 \\
\hline & ISDT $_{\text {rate }}$ & -.00518 & .13099 & .819 \\
\hline
\end{tabular}

The results of the paired t-test shown in Table 4 confirm that the relative performances of Finnish and French learners on GL and non-GL words differ significantly $(p<.05)$, no matter which penalty scoring algorithm is used.

For Chinese learners, a relatively small difference between GL and non-GL word knowledge was observed in Figure 2. Table 4 shows that this difference is significant $(p<.05)$ under the $h-f$ penalty calculation, but not significant when $\mathrm{I}_{\mathrm{SDT}}$ is used. As was mentioned in the introduction, Huibregtse et al. (2002) claimed that the $\mathrm{I}_{\mathrm{SDT}}$ algorithm takes better account of individual response styles than does $h-f$. It is probable, therefore, that a difference in individual response styles would account for the significances found under the two algorithms in the Chinese case, perhaps reflecting that this cohort tended to respond to unknown words with differing degrees of confidence.

In the above tables, standard deviations are presented alongside the results. It is interesting to note from Tables 2 and 3 that standard deviations on the French performances are especially low for the GL words, suggesting that it is a feature of the L1 (probably the existence of GL cognates) rather than individual performance which is mostly influencing the mean French score. For the French performance on non-GL words (as indeed for the Finnish and Chinese 
performances across the board), the standard deviations indicate that there is a reasonable spread of "yes" and "no" responses. This may be an effect of the tendency of French learners, previously noted, to report that they know any word which resembles a GL word found in French itself.

\section{Limitations of the Study}

In this study, no prior evaluation of vocabulary knowledge or language proficiency generally was carried out. Clearly, the strongest participants were the Finns, and the weakest were Chinese learners. If the proficiency of individuals had been established in advance (by some standard independent of the yes / no vocabulary test), it would have been possible to normalize their yes / no performances based on that information. This procedure would have preempted a possible objection to the validity of the results: namely, that the performance of learners of a given L1 is good on a category of words merely because learners in the country where that L1 is spoken are comparatively good at English. Certainly there is evidence that the Finnish people have strong English skills. Louhiala-Salminen and Kankaanranta (2012), for example, report that in the Finnish international companies they studied, $70 \%$ of internal communication in English was between non-native English speakers. Finland, according to Saarinen (2012), has become known as "Little England" on account of the high number of English-taught university programmes, second only to Holland in continental Europe, and is the current second choice for those not accepted to study in the UK.

It is important to note, however, that even without advance knowledge of proficiency and consequent normalization, patterns of performance in GL and non-GL words do emerge fairly clearly anyway. A learner's overall vocabulary level depends on his or her overall language proficiency, but variation in the proportion of GL to non-GL words is more intuitively ascribed to the learner's particular L1 than to proficiency.

Some readers may view the findings as somewhat predictable. Is it so surprising that participants with GL cognates in their own L1s know more GL cognates in English? First, it was actually the Finnish participants who turned out to know the greatest number of GL words, while the proportion of GL words to Germanic words known was lower than the French speakers. Furthermore, this study serves as a useful pilot to further planned research, described in the next section.

Some further limitations of the study arise from the participant sample and setting. As with many studies of this type, the results would be more reliable if the number of participants had been greater. Furthermore, the participants were enrolled at universities in Finland or the UK. There might have been some variation because of the different provenance of the data; for example, the learning participants received might differ from one academic English programme to another. To reduce the effect of possible artefacts, the study would ideally have been conducted at a single institution, or at least at two institutions in a single English-speaking or non English-speaking country.

Although participation in the research was voluntary and was authorized by the rather stringent ethics procedures by which the authors are bound at their institution, there is a possibility that some participants might have felt some coercion to participate, and this may have had an impact on the reliability of the data. However, the students were told clearly that the activity would not affect their grades. 


\section{Conclusions and Implications for Future Work}

This study focused on the variation in GL and non-GL word knowledge among learners of different L1 backgrounds. The participants were studying either business or engineering, in roughly equal numbers. In a future study, the authors will probably hypothesize that students of engineering will have larger GL vocabularies than business students, and that this is to do with the more technical vocabulary needed for engineering studies. If that hypothesis is supported, there will be a clear case for differentiation of the types of vocabulary taught in these and, potentially, other disciplines. This will have interesting implications for the on-going EGAP / ESAP debate.

The implications of the findings for teaching EAP in EFL contexts where students share an L1 are that vocabulary teaching and learning should take account of the particular needs of the L1 learner group. In settings where classes include mixed L1 groups, instructors may need to be aware of the variation in perceptions of word difficulty among students of different linguistic origins.

It has been demonstrated that some learners of some L1 backgrounds are more likely than others to need particular help with words of Graeco-Latin origin. It is therefore worth tuning those learners' vocabulary exposure to this kind of lexis. Practitioners could also explicitly teach Greek and Latin compound elements (e.g., peri- and tele-, -meter and-scope respectively), by basing tasks and activities on them to encourage productive learning and context guessing. This suggestion builds on the work of Zheng and Nation (2013) on the word part technique, a technique for learning vocabulary through the use of morphemes which are common to different words, especially GL words.

The authors of the present article have found from their own teaching practice that the word part technique works and is appreciated by students. Students enjoy, for example, the task of trying to predict the meaning of periscope, given their knowledge of telescope and perimeter.

When conducting the yes / no tests in class, the authors found that the students responded well and were intrigued by the task. Some students were apparently amused by some of the more obvious non-words, and very engaged when more difficult words or less obvious non-words appeared. There appears to be no existing literature on the possibility, but it does seem plausible that the yes / no test could be used as an occasional classroom activity, probably with immediate feedback. Further research would need to be done to see if there were any positive learning outcomes.

It was stated in the introduction that the GL vocabulary of English tends to represent scientific, technical, and overall more difficult concepts for native speakers than non-GL words. In this study, it has been shown that learners of certain L1 backgrounds also find GL words more difficult than speakers of languages such as French, in which almost all the lexical stock is composed of GL words. There is a statistically significant difference in learners' knowledge of GL and non-GL words, and this difference depends on the GL / non-GL status of the learner's L1. 


\section{Author Note}

Simon Smith, Department of English and Languages, Faculty of Business, Environment and Society, Coventry University, UK; Nicole Keng, Language Centre, Xi'an Jiaotong Liverpool University, Suzhou, China.

Nicole Keng is now at Department of English and Languages, Faculty of Business, Environment and Society, Coventry University, UK.

The BAWE data in this study come from the British Academic Written English (BAWE) corpus, which was developed at the Universities of Warwick, Reading and Oxford Brookes under the directorship of Hilary Nesi and Sheena Gardner (formerly of the Centre for Applied Linguistics [previously called CELTE], Warwick), Paul Thompson (Department of Applied Linguistics, Reading) and Paul Wickens (Westminster Institute of Education, Oxford Brookes), with funding from the ESRC (RES-000-23-0800). Thanks to Hilary Nesi of Coventry University and Paul Nation of Victoria University of Wellington for advice and support on this project.

Correspondence concerning this article should be addressed to Simon Smith, Department of English and Languages, Coventry University, Priory St., Coventry CV1 5FB, UK. E-mail: simon.smith@coventry.ac.uk 


\section{References}

Cobb, T. (2000). One size fits all? Francophone learners and English vocabulary tests. Canadian Modern Language Review, 572), 295-324. http://dx.doi.org/10.3138/cmlr.57.2.295

Corson, D. (1982). The Graeco-Latin (G-L) Instrument: A new measure of semantic complexity in oral and written English. Language and Speech, 25(1), 1-10.

Corson, D. (1985). The lexical bar. Oxford: Pergamon Press.

Coxhead, A. (2000). A new academic word list. TESOL Quarterly, 34(2), 213-238. http://dx.doi.org/10.2307/3587951

Henriksen, B. (2012, December). Something rotten in the Danish language classrooms? A short overview of the research on vocabulary size and depth of Danish learners of English. Paper presented at Swansea University.

Huibregtse, I., Admiraal, W., \& Meara, P. (2002). Scores on a yes-no vocabulary test: Correction for guessing and response style. Language Testing, 19(3), 227-245. http://dx.doi.org/10.1191/0265532202lt229oa

Laufer, B., \& Goldstein, Z. (2004). Testing vocabulary knowledge: Size, strength, and computer adaptiveness. Language Learning, 54(3), 399-436. http://dx.doi.org/10.1111/j.00238333.2004.00260.x

Louhiala-Salminen, L., \& Kankaanranta, A. (2012). Language as an issue in international internal communication: English or local language? If English, what English? Public Relations Review, 38(2), 262-269. http://dx.doi.org/10.1016/j.pubrev.2011.12.021

Meara, P., \& Buxton, B. (1987). An alternative to multiple choice vocabulary tests. Language Testing, 4(2), 142-154. http://dx.doi.org/10.1177/026553228700400202

Meara, P., \& Jones, G. (1990). The Eurocentres' 10K vocabulary size test. Zurich, Switzerland: Eurocentres Learning Service.

Nation, P. (1990). Teaching and learning vocabulary. New York: Newbury House.

Nation, P., \& Gu, P. Y. (2007). Focus on vocabulary. Sydney, Australia: National Centre for English Language Teaching and Research.

Nesi, H., \& Gardner, S. (2012). Genres across the disciplines: Student writing in higher education. Cambridge: Cambridge University Press

Nurweni, A., \& Read, J. (1999). The English vocabulary knowledge of Indonesian university students. English for Specific Purposes, 18(2), 161-175. http://dx.doi.org/10.1016/S0889-4906(98)00005-2

Pellicer-Sánchez, A., \& Schmitt, N. (2012). Scoring yes-no vocabulary tests: Reaction time vs. nonword approaches. Language Testing, 29(4), 489-509. http://dx.doi.org/10.1177/0265532212438053

Saarinen, T. (2012). Internationalization of Finnish higher education - Is language an issue? International Journal of the Sociology of Language, 2012(216), 157-173. http://dx.doi.org/10.1515/ijsl-2012-0044

Schmitt, N., Schmitt, D., \& Clapham, C. (2001). Developing and exploring the behaviour of two new versions of the Vocabulary Levels Test. Language Testing, 18(1), 55-88. http://dx.doi.org/10.1177/026553220101800103

Vilkaitè, L., Gyllstad, H., \& Schmitt, N. (2013, April). Vocabulary size and EAP: Evaluating the Vocabulary Size Test. Paper presented at BALEAP Conference, Nottingham University.

Zheng, W., \& Nation, P. (2013). The word part technique. Modern English Teacher, 22(1), 1216. 